\title{
KOMIK SEBAGAI MEDIA PEMBELAJARAN STATISTIKA
}

\author{
Edwin Adrianta Surijah, I Made Feby Anggara, Kadek Indah Yanti, Ni Luh \\ Wahyu Santika Sari, Listiyani Dewi Hartika, Ni Putu Rizky Eka Ramayanti, \\ Komang Ayu Asteria Asawisti Sukma Sugiri
}

\author{
Universitas Dhyana Pura \\ edwin@adrianta.com
}

\begin{abstract}
Statistics as a tool in Psychology often being considered as difficult by students. This research aimed to examine effectiveness of comic as learning tool to improve Statistics achievement. Participants of this research were thirty undergraduate students and divided into three groups, Experiment (receive Statistics comic as treatment), Control (no treatment), and Comparison (receive conventional material). The effectiveness of comic were showed in changes in Statistics achievement test results (between group experimental design). The result showed significant changes on each group before and after learning. Experiment Group exhibited most impactful change that evidenced can improve students' achievement in Statistics.
\end{abstract}

Keywords: learning tool, comic, Statistics subject in psychology

\begin{abstract}
Abstrak
Statistika di ranah pendidikan Psikologi seringkali menjadi materi kuliah yang ditakuti oleh mahasiswa. Penelitian ini hendak menguji efektivitas penggunaan komik sebagai media pembelajaran Statistika. Tiga puluh mahasiswa menjadi partisipan penelitian dan dibagi menjadi tiga kelompok, Kelompok Eksperimen (menerima pembelajaran melalui komik Statistika), Kelompok Kontrol (tidak menerima perlakuan), dan Kelompok Pembanding (menerima pembelajaran metode konvensional). Efektivitas diukur dari perubahan skor yang diperoleh pada alat ukur prestasi belajar Statistika (between group experimental design). Hasil analisis statistik menunjukkan ada perubahan berarti pada masing-masing kelompok sebelum dan sesudah pembelajaran namun Kelompok Eksperimen menunjukkan perubahan yang paling signifikan. Bahasan memaparkan keunggulan penggunaan komik dan disarankan untuk digunakan untuk meningkatkan prestasi belajar Statistika bagi mahasiswa.
\end{abstract}

Kata kunci: media pembelajaran, komik, statistika

\section{PENDAHULUAN}

Statistika merupakan salah satu ilmu yang penting untuk dikuasai. Data-data berbentuk numerik semakin banyak disajikan (Ben-Zvi \& Garfield, 2010). Statistika 
memainkan peran penting dalam desain studi ilmiah, analisis data ilmiah, interpretasi hasil, dan penarikan pernyataan konklusif (Eunsil, Jiyoung, \& Hae-young. 2014). Pentingnya statistika dan metode penelitian dalam program sarjana psikologi telah diakui oleh British Psychological Society (2006). Namun, bukti empiris dan opini subjektif pada umumnya menyatakan bahwa statistika adalah salah satu mata pelajaran yang paling tidak disukai oleh siswa.

Berdasarkan, penelusuran peneliti terhadap prestasi belajar mahasiswa pada matakuliah berkaitan pengukuran dan statistika pada Program Studi Psikologi di salah satu universitas. Data pada tabel 1 menunjukkan bahwa ada mahasiswa yang memperoleh nilai di bawah A dan B. Nilai yang tidak memuaskan tersebut membawa dampak pada indeks prestasi kumulatif.

Tabel 1

Data Prestasi Belajar terkait Statistika

\begin{tabular}{lccc}
\hline Nama Matakuliah & $\begin{array}{c}\text { Frekuensi } \\
\text { Nilai A dan B }\end{array}$ & $\begin{array}{c}\text { Frekuensi } \\
\text { Nilai C }\end{array}$ & $\begin{array}{c}\text { Frekuensi } \\
\text { Nilai C dan D }\end{array}$ \\
\hline Statistika & 30 & 14 & 16 \\
Konstruksi Alat Ukur & 12 & 18 & 5 \\
Psikometri & 8 & 9 & 18 \\
\hline
\end{tabular}

Selain data objektif, peneliti juga melakukan wawancara kepada beberapa mahasiswa Psikologi untuk mendapatkan data subjektif terhadap mahasiswa yang memperoleh nilai Statisika di bawah A dan B. Hasilnya menyatakan bahwa mahasiswa: 1) tidak menyukai dan merasa tidak mampu dalam pelajaran matematika; 2) kurang mampu memahami metode pembelajaran; 3) pasrah karena dari awal sudah merasa mendapatkan nilai dibawah standar; 4) merasa kelelahan karena mata kuliah statistika dijadwalkan pada malam hari; 5) tidak mengetahui standar penilaian yang ditentukan oleh dosen serta 6) memiliki kesibukan diluar jadwal perkuliahan.

Untuk lebih memperkuat fenomena mengenai rendahnya nilai mata kuliah yang berkaitan dengan statistika, peneliti melakukan suatu survei. Survei yang dilakukan mengenai mata kuliah psikologi yang paling tidak diminati oleh mahasiswa di salah satu Universitas. Sebanyak 22 partisipan mengisi survei dengan memilih angka 1 (untuk mata kuliah yang paling disukai) sampai 8 (untuk mata kuliah yang paling tidak disukai). Dari tabel 2 dapat dilihat bahwa mata kuliah yang paling tidak diminati adalah statistika dengan rerata 5,3 atau dengan rerata yang paling tinggi. 
Keseluruhan data objektif dan subjektif yang peneliti peroleh menunjukkan adanya permasalahan pembelajaran terhadap matakuliah yang berkaitan dengan statistika atau pengolahan data kuantitatif. Mahasiswa tidak memiliki motivasi dan merasa tidak mampu dalam menguasai materi-materi terkait matakuliah tersebut. Mahasiswa memiliki sikap yang cenderung negatif terhadap statistika.

Tabel 2

Rata-Rata Peminatan Terhadap Mata Kuliah

(Semakin Besar Skor Semakin Tidak Diminati)

\begin{tabular}{llllllll}
\hline \multicolumn{7}{c}{ Mata Kuliah } \\
\hline Psikologi & Psikologi & Psikologi & Psikologi & Psikologi & Psikologi & Metodologi & Statistika \\
Kepribadian & Umum & Belajar & $\begin{array}{l}\text { Industri \& } \\
\text { Organisasi }\end{array}$ & Sosial & Faal & Penelitian & \\
3,8 & 4,3 & 4,4 & 4,4 & 4,4 & 4,5 & 4,9 & 5,3 \\
\hline
\end{tabular}

Penelitian terdahulu menunjukan bahwa sikap terhadap statistika secara positif berkorelasi dengan prestasi mahasiswa dalam kelas tersebut. Semakin positif sikap yang ditunjukan maka semakin tinggi prestasi statistika yang dimiliki (Chiesi \& Primi, 2009; Dempster \& McCorry, 2009). Kesulitan mahasiswa untuk memahami konsep statistika, membuat mereka memiliki masalah dalam menangani disiplin ilmu ini dan mencapai tingkat kinerja yang rendah (Chiesi \& Primi, 2009; Dempster \& McCorry, 2009). Dalam pembelajaran mata kuliah statistika, mahasiswa menghadapi rumusan yang rumit yang membuat mereka merasa dibawah tekanan dan sulit untuk memahami konsep-konsep tertentu (Sahari, 2011).

Berdasarkan permasalahan yang peneliti temui, peneliti ingin mengkaji dan menemukan cara inovatif untuk mengatasi hambatan dalam pembelajaran terkait statistika. Peneliti kemudian menelusuri penelitian terdahulu mengenai pengukuran prestasi belajar statistika. Peneliti juga menelusuri metode-metode apa saja yang pernah diupayakan sebelumnya untuk mengatasi permasalahan belajar statistika.

Budé et al. (2007) meneliti prestasi belajar statistika mahasiswa dalam kaitannya dengan motivasi dan persistensi mahasiswa untuk belajar. Penelitian tersebut menggunakan hasil ujian sebagai pengukuran terhadap prestasi belajar statistika. Soal ujian terdiri dari tiga puluh butir pertanyaan pilihan ganda. Rentang nilai adalah 0 sampai dengan 10 . Chiesi dan Primi (2009) dalam penelitiannya mengenai prestasi akademik statistika menuliskan bahwa seringkali kemampuan matematika menjadi dasar pengukuran prestasi statistika dengan asumsi bahwa matakuliah statistika membutuhkan kemampuan dasar berhitung. Nilai prestasi belajar matematika pada waktu SMA seringkali dijadikan acuan kemampuan statistika mahasiswa. Peneliti tersebut kemudian juga menyusun tes prestasi 
statistika tersendiri yang terdiri dari enam domain yaitu: operations, fractions (keduanya berkaitan dengan memahami hasil statistika deskriptif), set theory (memahami konsep probabilitas dalam pengujian statistik), first order equations (berkaitan dengan analisis regresi), relations (memahami koefisien korelasi), dan probability (memaknai pengujian hipotesis).

Peneliti juga menelusuri hasil meta-analisis terkait prestasi belajar statistika. Emmioğlu dan Capa-Aydin (2012) menemukan ada banyak cara atau pendekatan dalam pengukuran prestasi statistika. Pengukuran yang paling umum digunakan adalah nilai hasil belajar (indeks prestasi matakuliah terkait) atau nilai ujian mahasiswa. Ada pula penelitian yang menggunakan tes terstandardisasi seperti Statistics Reasoning Assessment dan Statistics Concept Inventory.

Berdasarkan penelusuran tersebut, peneliti menemukan bahwa ada banyak cara untuk mengukur prestasi statistika. Alat ukur seperti tes standar hingga penggunaan nilai ujian menjadi cara yang pernah dipakai dalam penelitian sebelumnya. Pada konteks penelitian ini, peneliti memutuskan untuk menyusun sendiri butir-butir tes prestasi yang berkaitan dengan statistika. Hal ini didasarkan pada keyakinan peneliti bahwa matakuliah yang mengandung elemen statistika tidak hanya pada matakuliah Statistika saja namun juga pada matakuliah lainnya seperti Psikometrika, Konstruksi Alat Ukur, dan Metode Penelitian. Alat ukur yang disusun berdasarkan konteks penelitian dilangsungkan akan membantu tes prestasi mengukur dengan lebih akurat.

Peneliti kemudian melanjutkan dengan menelusuri media belajar ataupun intervensi yang umum digunakan untuk meningkatkan prestasi belajar. Waluyanto (2005) menyatakan media pembelajaran merupakan salah satu faktor yang berpengaruh terhadap prestasi belajar mahasiswa. Shabiralyani et al. (2015) menemukan bahwa mayoritas guru dan siswa memiliki persepsi positif terhadap penggunaan media gambar dalam proses pembelajaran. Komik merupakan salah satu media gambar yang dapat digunakan sebagai metode yang dapat mempermudah proses pembelajaran. Melalui komik, ide-ide ilmiah dan materi pendidikan disampaikan melalui karya seni yang mengesankan (Tatalovic, 2009). Penelitian Puspitorini et al. (2014) menunjukan bahwa penggunaan media komik dalam pembelajaran mampu meningkatkan motivasi belajar, serta hasil belajar ranah kognitif dan afektif. Avrilianti (Pratama et al., 2017) menyatakan beberapa kelebihan dari komik sebagai media pembelajaran dalam bentuk visual. Pertama, media visual dapat memperlancar pemahaman dan memperkuat ingatan. Kedua, media visual dapat pula menumbuhkan minat siswa dan dapat memberikan hubungan antara isi materi pelajaran dengan dunia nyata. Terakhir, kualitas gambar komik dapat meningkatkan kualitas pembelajaran.

Berdasarkan penelusuran tersebut, penelitian ingin menguji efektivitas media pembelajaran statistika melalui komik dalam meningkatkan prestasi belajar statistika mahasiswa. Penelitian ini juga hendak mengungkap sikap responden terhadap komik 
yang digunakan sebagai media pembelajaran Statistika. Metode ini diharapkan dapat memudahkan proses penyampaian dan pemahaman materi statistika selama proses pembelajaran berlangsung.

\section{METODE}

\section{Partisipan}

Partisipan penelitian ini adalah mahasiswa yang mendapat nilai statistika yang masih memenuhi standar dan/atau di bawah standar ketentuan. Standar nilainya adalah A $(80,00$ sampai dengan 100); B (65,00 sampai dengan 79,99); C (55,00 sampai dengan 64,99); D (40,00 sampai dengan 54,99); E (0,00 sampai dengan 39,99). Peneliti menggunakan hasil pilot study untuk menentukan sampel dalam penelitian. Pendekatan yang digunakan untuk menentukan batasan nilai untuk menjadi partisipan adalah cut-off score. Peneliti menentukan standar nilai bukan dari rerata skor yang diperoleh partisipan dalam pilot study, namun mengacu pada standar nilai yang dicantumkan dalam buku pedoman akademik. Hasilnya, peneliti menemukan 27 mahasiswa yang mendapat nilai C, D dan E. Keseluruhan mahasiswa tersebut direkrut menjadi partisipan dengan meminta kesediaan menjadi partisipan. Penulis juga menjelaskan bahwa mereka dapat mengundurkan diri dari penelitian (tanpa paksaan).

Partisipan tersebut dibagi menjadi tiga kelompok yaitu Kelompok Eksperimen (menerima pembelajaran dengan media komik yang bermuatan materi statistika dasar), Kelompok Kontrol (tidak menerima perlakuan sama sekali), dan Kelompok Pembanding (menerima pembelajaran berupa materi statistika dasar konvensional). Seluruh partisipan dikelompokkan secara random (random assignment) yang artinya semua partisipan memiliki kesempatan yang sama untuk masuk ke dalam salah satu dari tiga kelompok tersebut. Hasilnya masing-masing kelompok terdiri dari 9 partisipan.

\section{Instrumen}

Alat ukur yang digunakan dalam penelitian ini adalah soal yang memuat materi statistika yang disusun oleh peneliti berdasarkan indikator dari pembelajaran statistika. Skala tes prestasi statistika disusun dalam bentuk pilihan ganda yang berjumlah 35 butir. Skala tes prestasi statistika digunakan untuk mengetahui sejauh mana pemahaman partisipan terhadap materi statistika. Aspek-aspek yang menjadi acuan penyusunan skala ini dan koefisien reliabilitasnya tercantum pada Tabel 3.

Berdasarkan pilot study, diperoleh 35 butir soal dengan koefisien reliabilitas sebesar 0.647. Hal tersebut menunjukkan bahwa alat ukur tes prestasi reliabel. Partisipan yang digunakan dalam penelitian ini adalah seluruh partisipan dalam pilot study. Jadi peneliti mengacak nomor beberapa butir soal dan mengubah angka-angka pada soal hitungan. 
Tujuannya adalah untuk meminimalisir terjadinya bias akibat proses belajar dalam penelitian.

Tabel 3

Blueprint Soal Tes Prestasi Statistika Dasar

\begin{tabular}{lcc}
\hline \multicolumn{1}{c}{ Aspek } & Jumlah Butir & KR 20 \\
\hline $\begin{array}{l}\text { Aspek Pengetahuan (mengukur } \\
\text { kemampuan hafalan konsep- } \\
\text { konsep statistika) }\end{array}$ & 17 & \\
$\begin{array}{l}\text { Aspek Pemahaman (mengukur } \\
\text { kemampuan aplikasi statistika } \\
\text { dasar dan mengerti logika di balik } \\
\text { pengukuran/ korelasi }\end{array}$ & 11 & 0.647 \\
Aspek Pemahaman dan Analisis & & \\
\hline
\end{tabular}

\section{Pembelajaran (Media Gambar Komik)}

Peneliti menggunakan komik sebagai media belajar yang peneliti asumsikan dapat meningkatkan prestasi statistika. Sebelum komik digambar, peneliti menyusun materi secara tertulis. Materi tersebut kemudian menjadi dasar penyusunan alat tes prestasi belajar Statistika dan pembuatan komik. Materi yang dimuat dalam komik itu peneliti susun sesuai dengan aspek pada blueprint Tabel 3. Materi tertulis ini yang peneliti berikan kepada partisipan Kelompok Pembanding. Setelah itu peneliti menelusuri pembuat komik profesional untuk mendapatkan komik dengan kualitas yang baik. Peneliti meninjau dengan teratur proses pembuatan komik tersebut agar isi ceritanya sesuai dengan materi. Selain itu, peninjauan dilakukan agar penulis komik menyelesaikan tepat waktu. Komik yang digunakan belum direvisi karena jeda waktu antara selesainya pengerjaan komik dengan waktu untuk melakukan eksperimen sangat dekat. Komik diberikan secara digital kepada Kelompok Eksperimen dengan pemberitahuan supaya tidak dilihat atau dibaca oleh mahasiswa/partisipan lain.

\section{Desain Eksperimen}

Peneliti memilih rancangan True Experiment dalam penelitian ini. Desain True Experiment yang digunakan adalah Randomized Pretest-Posttest Control Group Design. Dalam desain ini terdapat tiga kelompok yang dipilih secara random, Kelompok Eksperimen (KE), Kelompok Kontrol (KK) dan Kelompok Pembanding (KP).

Peneliti memberikan pretes kepada tiga kelompok untuk mengetahui pengetahuan awal tentang statistika. Dalam pelaksanaan pembelajaran, Kelompok Eksperimen diberikan komik digital/virtual yang memuat materi statistika dasar. Pada Kelompok 
Pembanding, peneliti memberikan materi statistika dasar tertulis. Sedangkan Kelompok Kontrol tidak mendapat pembelajaran sama sekali. Kelompok Eksperimen dan Pembanding membaca materi di rumah masing-masing dengan pengawasan peneliti selama rentang waktu 1 minggu. Peneliti memastikan apakah materi yang dibagikan sudah dibaca oleh partisipan melalui grup chatting. Setelah pemberian pembelajaran kepada Kelompok Eksperimen dan Pembanding, tiga kelompok diberikan postes.

Tabel 4

Desain Eksperimen

\begin{tabular}{lllll}
\hline & Kelompok & Pretest & Perlakuan/Pembelajaran & Posttest \\
\cline { 2 - 5 } R & KE & O1 & Pembelajaran melalui Komik & O2 \\
& KK & O1 & Tidak Ada Pembelajaran & O2 \\
& KP & O1 & Pembelajaran Tertulis & O2 \\
\hline
\end{tabular}

Analisis Data.

Peneliti melakukan uji beda pada hasil pengukuran pretes dan postes masing-masing kelompok dengan Wilcoxon Signed Rank Test. Untuk membandingkan postes antar kelompok, peneliti menggunakan Mann Whitney U Test. Peneliti juga mendeskripsikan statistik pengaruh pemberian media pembelajaran komik terhadap prestasi statistika.

\section{HASIL}

Tabel 5 menunjukkan bahwa rata-rata kelompok kontrol terjadi kenaikan. Namun, peningkatan tidak signifikan. Pada Kelompok Pembanding (Pembelajaran Tertulis) dapat dilihat bahwa rata-rata nilai partisipan juga mengalami peningkatan yang lebih tinggi dari Kelompok Kontrol.

Tabel 5

Rata-Rata Pretes dan Postes Tiga Kelompok dan Wilcoxon Test

\begin{tabular}{rrrrcrrr}
\hline Kelompok & Pretes & Postes & $\mathbf{Z}$ & $\begin{array}{c}\text { One } \\
\text { Tailed } \\
\text { Sig. }\end{array}$ & W & $\mathbf{W}_{\text {tabel(0,05) }}$ & $\begin{array}{c}\text { Korelasi } \\
\text { Spearman }\end{array}$ \\
\hline Kontrol & 46.2 & 44.4 & 0.051 & 0.480 & & & 0,250 \\
Tertulis & 43.0 & 46.6 & -- & & 27 & 5 & 0,836 \\
Komik & 45.8 & 57.33 & 1.682 & 0.046 & & & 0,297 \\
\hline
\end{tabular}


Tabel hasil skoring pretes dan postes dari Kelompok Eksperimen (Pembelajaran Media Komik) menunjukkan bahwa rerata nilai partisipan mengalami peningkatan yang cukup signifikan dengan uji satu arah (one tailed). Hasil uji Wilcoxon Signed-ranks Test menunjukkan bahwa rata-rata postes Kelompok Eksperimen (Pembelajaran Media Komik) $(57,33)$ berbeda secara siginifikan dibandingkan dengan hasil pretes Kelompok Eksperimen (45,8), $\mathrm{Z}=1,682, \mathrm{p}<0,05, \mathrm{r}=0.297$. Pada Kelompok Pembelajaran Tertulis juga terjadi perbedaan rata-rata yang signifikan antara pretes $(43,0)$ dan postes $(46,6)$ dengan $\mathrm{W}=27$, dengan $\mathrm{p}$ nilai $\mathrm{W}_{\text {tabel }}$ dengan signifikan. $05=5$, dan dengan nilai $\mathrm{r}=0,918$. Sementara hasil pretes dan postes dari Kelompok Kontrol menunjukkan perbedaan yang tidak signifikan yaitu rata-rata pretes $(46,2)$ dan postes $(44,4)$, dengan $\mathrm{Z}=0,051$ dengan p $0,250, r=0,25$.

Peneliti juga melakukan uji beda Mann Whitney $U$ untuk membandingkan hasil posttest antara tiga kelompok.

Tabel 6

Hasil Uji Beda Mann Whitney U

\begin{tabular}{lrccc}
\hline \multicolumn{1}{c}{ Kelompok } & $\begin{array}{l}\text { Rata-Rata } \\
\text { Rank Postes }\end{array}$ & U & \multicolumn{1}{c}{$\mathbf{Z}$} & Sig. \\
\hline Tanpa Pembelajaran & 6,72 & 28 & -1.625 & .052 \\
Komik & 12.28 & & & \\
\hline $\begin{array}{l}\text { Tanpa Pembelajaran } \\
\text { Tertulis }\end{array}$ & 9,06 & \multirow{2}{*}{48.5} & -0.075 & .468 \\
\hline Komik & 9,94 & & & \\
Tertulis & 7.06 & \multirow{2}{*}{30} & -1.474 & .072 \\
\hline
\end{tabular}

Pada uji Mann Whitney $U$ ada tidak perbedaan hasil postes antar tiga Kelompok Pembelajaran (Komik, Tidak Pembelajaran, Tertulis). Sekalipun tidak ada perbedaan rata-rata ranking postes antar tiga kelompok tersebut, namun ada perbedaan yang hampir signifikan yaitu antara kelompok pembelajaran media komik dengan kelompok tanpa pembelajaran.

\section{PEMBAHASAN}

Penelitian ini hendak menjawab apakah media gambar atau komik dapat membantu mahasiswa memahami materi yang terkait dengan statistika psikologi. Hasil pengujian hipotesis menunjukkan bahwa rata-rata nilai yang diperoleh oleh Kelompok Pembelajaran Media Komik lebih tinggi dibandingkan nilai rata-rata sebelum membaca komik. Hal ini berarti media gambar atau komik membantu partisipan pada Kelompok Eksperimen 
mamahami materi dengan efeketif. Namun kefektifan ini tidak didukung perbandingan postes antar kelompok. Artinya peningkatan ini tidak membuat metode pembelejaran media komik tidak lebih baik dibanding metode tertulis. Namun demikian ada kecenderungan media komik lebih baik jika menggunakan partisipan yang lebih banyak.

Temuan ini sejalan dengan penelitian terdahulu yang membahas berbagai kegunaan komik dalam peningkatan efektivitas pengajaran. Dalam beberapa penelitian terdahulu, ditemukan berbagai kegunaan komik sebagai strategi mengajar. Karap (2017) meneliti tentang penggunaan komik sebagai media untuk memudahkan dalam pemahaman bahasa asing. Dalam penelitiannya ditemukan bahwa komik dapat membantu siswa untuk mengurangi rasa cemas saat menerima pelajaran bahasa asing.

Silva et al. (2017) meneliti tentang kegunaan komik sebagai strategi mengajar mahasiswa program studi manajemen. Dalam penelitiannya, ditemukan bahwa komik berfungsi untuk meningkatkan perkembangan kompetensi, membantu dalam pengembangan inovasi dan fleksibilitas. Komik juga berkontribusi dalam mereduksi gap antara teori dengan praktik. Sebagai tambahan, komik dapat membantu mahasiswa dalam mengembangkan pemikiran yang kritis serta membantu dalam pengambilan keputusan. Siswa juga dapat menebak makna dari istilah asing karena bantuan gambar pada komik. Terakhir, siswa yang menggunakan komik dibandingkan media teks tertulis dapat lebih mudah untuk memanggil kembali (recall) makna dari suatu kata.

Muzumdar (2016) juga menemukan beberapa kegunaan komik. Ditemukan bahwa komik dapat meningkatkan motivasi siswa untuk membaca. Selain itu siswa juga dibantu untuk menghafal konten dalam komik serta membuat proses belajar menjadi lebih menyenangkan. Jadi, efektivitas komik dalam proses pembelajaran sudah terbukti pada beberapa penelitian terdahulu.

Komik atau media gambar yang isinya berkaitan dengan materi statistik memang terbukti dapat meningkatkan pemahaman mahasiswa atau partisipan. Akan tetapi, ada faktor-faktor lain yang dapat meningkatkan kemampuan atau pemahaman mahasiswa. Peneliti mencoba menelusuri beberapa penelitian terdahulu mengenai faktor-faktor yang juga membantu untuk meningkatkan prestasi statistika.

Kalaian dan Kasim (2014) melakukan penelitian tentang pengaruh pembentukkan kelompok kecil untuk meningkatkan prestasi statistika siswa. Dalam penelitiannya dilakukan meta-analisis yang menunjukkan bahwa metode belajar kooperatif, kolaborasi dan penyelidikan dasar digunakan pada level kelas statistika di universitas. Hasil penelitian juga menunjukkan bahwa belajar secara kooperatif dan kolaboratif mendukung keefektivitasan pembelajaran dalam kelompok kecil. Jadi secara keseluruhan, metode belajar dengan menggunakan kelompok kecil dapat meningkatkan nilai ujian statistika mahasiswa. 
Sun et al. (2015) meneliti tentang bagaimana penilaian antar siswa (peer assessment) dapat meningkatkan prestasi belajar statistika. Ditemukan bahwa siswa yang mengikuti peer assessment memiliki performa yang secara siginifikan lebih baik saat kuis dari pada yang tidak mengikuti. Siswa juga mampu menjawab pertanyaan saat ujian dengan lebih baik. Jadi hasil penelitian ini juga menunjukkan faktor selain komik yang dapat meningkatkan prestasi statistika. Dari beberapa temuan tersebut dapat diketahui bahwa ada metode lain selain komik yang juga dapat meningkatkan prestasi statistika.

Penelitian ini memiliki kelemahan seperti penggunaan alat ukur prestasi belajar yang belum sepenuhnya akurat. Ada beberapa hal yang dapat ditingkatkan guna mengkaji efektivitas komik sebagai media pembelajaran Statistika. Pertama, prosedur pengukuran pretes dan postes agar menggunakan tes yang berbeda namun paralel. Penggunaan tes yang sama pada pretes dan postes dalam penelitian ini berdampak pada efek pengulangan tes. Jika menggunakan tes paralel yang memiliki tingkat kesulitan dan konsep penyusun yang serupa maka persoalan pengulangan tes akan terhindari (Kaplan \& Saccuzzo, 2009).

Salah satu cara lain yang dapat ditempuh adalah menggunakan pengukuran pembanding yaitu tes. Davison dan Dustova (2017) menemukan dalam penelitiannya bahwa tes prestasi yang terstandardisasi belum tentu mengungkap atau sungguh-sungguh mengukur kemampuan yang ditujukan. Salah satu pengukuran yang umum dipakai untuk asesmen kesuksesan siswa adalah indeks prestasi dan hasil ujian siswa yang terkait (York, Gibson, \& Rankin, 2015). Penggunaan nilai resmi tersebut juga memberikan nilai tambah berupa kemampuan prediktif variabel bebas dalam memengaruhi variabel tergantung (prestasi belajar).

Pengukuran pembanding lain yang dapat digunakan adalah penggunaan skala sikap. Penelitian ini menggunakan skala sikap namun baru pada analisis deskriptif sikap terhadap penggunaan komik. Salah satu alternatif yang dapat digunakan untuk penelitian selanjutnya adalah pengujian sikap terhadap subjek pelajaran (sikap terhadap statistika) (Köse, 2013). Peneliti dapat menguji apakah ada perbedaan sikap terhadap Statistika sebelum dan setelah menggunakan media gambar komik. Bolton-Gary (2012) dalam penelitiannya menggunakan data kualitatif sebagai data pembanding. Alat ukur pembanding yang telah diuraikan tersebut dapat mengatasi kelemahan dalam pengukuran yang sudah digunakan dalam penelitian ini.

Dari aspek komik yang digunakan sebagai media pembelajaran, penelitian ini memiliki keunggulan dibandingkan penelitian sebelumnya (Köse, 2013). Penelitian sebelumnya menggunakan kompilasi dari komik yang telah ada (telah dibuat). Penelitian ini menggunakan komik asli yang disusun berdampingan oleh penulis dan komikus. Di sisi lain kelemahan dari pendekatan ini adalah validasi materi komik. Penelitian selanjutnya dapat melakukan elisitasi kepakaran berupa memadukan pendapat/kritik beberapa pakar (Colson \& Cooke, 2018). Hal ini membantu keyakinan peneliti dalam memastikan ketepatan isi dari komik yang disusun. 


\section{DAFTAR PUSTAKA}

Ben-Zvi, D., \& Garfield, J. (2010). Introducing the emerging discipline of statistics education. School Science and Mathematics, 108(8), 355-361.

Bolton-Gary, C. (2012). Connecting through comics: Expanding opportunities for teaching and learning. US-China Education Review, 4, 389-395.

British Psychologycal Society. (2006). Regulations and reading list for the qualifying exam. Leicester, UK: BPS.

Bude, L., Wiel, M. W. J. V. D., Imbos, T., Candel, M. J. J. M., Broers, N. J., \& Berger, M. T. F. (2007). Student's achievements in a statistics course in relation to motivational aspects and study behaviour. Statistics Education Research Journal, $6(1), 5-21$.

Colson, A. R. \& Cooke, R. M. (2018). Expert elicitation: using the classical model to validate experts' judgments. Review of Environmental Economics and Policy, 12(1), 113-132. doi: https://doi.org/10.1093/reep/rex022

Davison, C. B. \& Dustova, G. (2017). A quantitative assessment of student performance and examination format. Journal of Instructional Pedagogies, 18, 1-10.

Emmioglu, E., \& Aydin, Y. C. (2012). Atitudes and achievement in statistics: a metaanalysis study. Statistics Education Research Journal, 11(2), 95-102.

Eunsil, C., Jiyoung, L., \& Haeyoung, K. (2014). Statistical methods used in articles published by the journal of periodontal and implant Science. Journal of of Periodontal and Implant Science, 44(06), 288-292.

Kaplan, R. M. \& Saccuzzo, D. P. (2009). Psychological testing: Principles, applications, and issues (7th. Ed.). Belmont, CA: Wadsworth.

Karap, Z. (2017). The possible benefits of using comic books in foreign language education: A classroom study. Training and Practice, 15(2), 243-260.

Köse, E. Ö. (2013). Effects of cartoons on students' achievement and attitudes in biology teaching (endocrine systems). Kastamonu Education Journal, 21(3), 931-944.

Martin, D. W. (2008). Doing psychology experiment (7th. Ed.). Belmont, CA: Wadsworth.

O’Connor, C. M., Norris, D. R., Crossin, G. T., \& Cooke, S. J. (2014). Biological carryover effect: Linking common concepts and mechanisms in ecology and evolution. Ecosphere, 5(3), 1-11.

Pratama, I., Gunarhadi, \& Priyono. (2017). Pengaruh penggunaan media grafis komik terhadap prestasi belajar IPA pada materi fungsi alat-alat tubuh siswa kelas V SLB B. Jurnal Penelitian Pendidikan, 20(1), 1-10. 
Puspitorini, R., Prodjosantoso, A. K., Subali, B., \& Jumadi. (2014). Penggunaan media komik dalam pembelajaran IPA untuk meningkatkan motivasi dan hasil belajar kognitif dan afektif. Jurnal Cakrawala Pendidikan, 33(3), 413-420.

Shabiralyani, G., Hasan, K. S., Hamad, N., \& Iqbal, N. (2015). Impact of visual aids in enhancing the learning process case research: district dera ghazi khan. Journal of Education and Practice, 19(6), 226-223.

Silva, A. B. D., Santos, G. B. T., \& Bispo, A. C. K. D. A. (2017). The comics as teaching strategy in learning of students in an undergraduate management program. Human and Social Management, 18(1), 40-46.

Tatalovic, M. (2009). Science comics as tools for science education and communication: a brief, exploratory study. Journal of Science Communication, 8(4), 1-17.

York, T. T., Gibson, C., \& Rankin, S. (2015). Defining and measuring academic success. Practical Assessment, Research \& Evaluation, 20(5), 1-20. 